\title{
SINTESIS KERAMIK COERDIERITE BERBASIS SILIKA SEKAM PADI SEBAGAI MATERIAL ISOLATOR LISTRIK
}

\author{
Ajo Dian Yusandika \\ Pendidikan Fisika IAIN Raden Intan Lampung; e-mail: ajodian@radenintan.ac.id \\ Diterima: 21 Maret 2016. Disetujui: 10 Oktober 2016. Dipublikasikan: Oktober 2016
}

\begin{abstract}
Availability of rice husk in abundant amount and the content of Silica in it, has aspect of utilization of agriculture residues that have not been developed. Cordierite ceramics have been synthesized using husk silica with the sol-gel method. The resulted Cordierite is in powder form and then pressed it in the form of pellets. Then, sintering the Pellet for 6 hours at a temperature of $1000^{\circ} \mathrm{C}, 1200^{\circ} \mathrm{C}$, and $1400^{\circ} \mathrm{C}$. To determine the structure of materials, Cordierite is characterized using XRD and DTA. Finally, measuring the electrical resistance of Cordierite to get the value of the resistivity.
\end{abstract}

Abstrak: Ketersediaan sekam padi dalam jumlah melimpah dan kandungan Silika yang ada di dalamnya, memiliki aspek pemanfaatan residu pertanian yang selama ini belum dikembangkan. Telah dilakukan sintesis keramik Cordierite menggunakan silika sekam padi.dengan metode sol-gel. Cordierite yang dihasilkan berbentuk serbuk dan kemudian dicetak dalam bentuk pellet. Pellet kemudian dsintering selama 6 jam pada suhu $1000^{\circ} \mathrm{C}, 1200^{\circ} \mathrm{C}$ dan $1400^{\circ} \mathrm{C}$. Untuk mengetahui struktur bahan maka dilakukan karakterisasi menggunakan XRD dan DTA. Selanjutnya dilakukan uji tahanan sehingga dididapatkan nilai resistansinya.

(C) 2016 Pendidikan Fisika FTK IAIN Raden Intan Lampung

Kata kunci: coerdierite, silika, sintering

\section{PENDAHULUAN}

Sistem tenaga listrik mulai dari pembangkitan, saluran transmisi, sampai dengan pendistribusian tenaga listrik memerlukan suatu pengaman (isolator). Isolator adalah bahan atau material yang memiliki sifat yang tidak dapat menghantarkan listrik maupun panas, seperti keramik, plastik, kayu, dan lainlain. Salah satu bahan yang memiliki kemampuan sebagai isolator listrik maupun panas adalah keramik. Kemampuan tersebut didukung dengan sifat keramik yakni kapasitas panas yang baik, konduktivitas panas yang rendah, dan tahan korosi.

Salah satu bahan keramik yang dikenal adalah Cordierite. Cordierite dikenal dengan rumus kimia $\mathrm{Mg}_{2} \mathrm{Al}_{4} \mathrm{Si}_{5} \mathrm{O}_{16}$ merupakan material keramik yang dapat digunakan untuk beragam aplikasi seperti katalis gas pada mobil, pengganti panas pada mesin gas turbin, industri pembakaran, pelapis material dalam elektronik, piranti optik, dan magnetik. Cordierite memiliki konstanta dielektrik yang rendah (Naskar, 2004), berkisar 9,3 serta dielectric strength 212, dan volume resistivitas > $10^{14}$. Berdasarkan karakteristik tersebut, Cordierite sangat baik untuk digunakan sebagai isolator tegangan tinggi. Selain itu, Cordierite memiliki koefisien ekspansi termal 1700 ${ }^{0} \mathrm{C}$ dan shock resistance $300{ }^{\circ} \mathrm{C}$. Sehingga dari karakteristik termal ini, Cordierite baik digunakan sebagai isolator suhu tinggi.

Pada umumnya, dalam pembuatan Cordierite dapat menggunakan Silika sintesis, mineral, dan nabati. Secara 
komersial Silika sintesis yakni TEOS (Tetraethylortosilicate) dan TMOS (Tetramethylortosilikat) sudah digunakan sebagai bahan pembuat Cordierite. Mineral yang mengandung Silika diantaranya pasir kuarsa (Amuni, 1998), lempung dan juga abu terbang batu bara sebesar 57, 50 \% (PT. Bukit Asam Tarahan, 2005) dan nabati diantaranya bambu, tongkol jagung, dan sekam padi. Dari ketiga sumber Silika nabati tersebut Silika sekam padi dengan mudah dapat diperoleh baik secara pembakaran maupun ekstraksi, dibandingkan dengan Silika sintesis dan mineral yang memerlukan biaya cukup tinggi dan sulit untuk diekstraksi. Dari penelitian sebelumnya, sekam padi diketahui mengandung Silika aktif dengan kadar cukup tinggi 87 - $97 \%$ berat sekam padi (Daifullah, dkk, 2004; Yalcin dan Sevinc, 2001; Sofyan, 2012) yang bersifat amorf, berbutiran halus, dan reaktif. Sintesis Coerdierite pada penelitian lainnya juga telah dilakukan menggunakan metode padatan pada suhu sintering $1200{ }^{0} \mathrm{C}$ dengan penambahan Alumina $\left(\mathrm{Al}_{2} \mathrm{O}_{3}\right)$ (Oktavianty, dkk, 2016). Selain itu, Badan Pusat Statistik (BPS) menunjukkan bahwa Provinsi Lampung menghasilkan padi sebanyak 2 ton/tahun, dari jumlah tersebut diperkirakan akan dihasilkan sekam padi sekitar $45 \%$ (Badan Pusat Statistik Provinsi Lampung, 2004).

Ketersediaan sekam padi dalam jumlah melimpah di Propinsi Lampung dan kandungan Silika yang ada di dalamnya, merupakan alasan praktis yang melatarbelakangi pengajuan penelitian ini dan memiliki aspek pemanfaatan residu pertanian untuk pembuatan produk bermanfaat yang selama ini belum dikembangkan. Sehingga berdasarkan pemaparan di atas, sekam padi berpotensi besar dapat digunakan sebagai bahan dasar pembuatan keramik Cordierite sebagai material isolator listrik yang tahan terhadap tegangan tinggi.

\section{LANDASAN TEORI}

\section{Sekam Padi}

Silika merupakan komponen utama yang terkandung dalam dari abu sekam padi, yakni berkisar $87-97 \%$ berat dari abu sekam padi (Daifullah, dkk, 2004 Chen dan Chang, 1991), yang secara alami bersifat amorf dan bertahan hingga temperature di bawah $800{ }^{\circ} \mathrm{C}$ (Della, dkk, 2002). Silika amorf mempunyai stabilitas rendah sehingga mudah beraksi (ponzolane) dengan pereaksi lain. Kereaktifan Silika dipengaruhi temperature pengabuan dengan keraktifan optimum ketika sekam padi di bakar pada temperatur $550-700{ }^{\circ} \mathrm{C}$ (Kalapathy, dkk, 2000) dan keraktifan menurun dengan naiknya temperatur di atas $800{ }^{\circ} \mathrm{C}$, akibatnya meningkatnya kristalinitas dalam bentuk tridmit, dan kristobalit (Shinohara dan Kohyama, 2004).

\section{Cordierite}

Cordierite adalah nama mineral dari bahan keramik dengan rumus kimia $\mathrm{Mg}_{2} \mathrm{Al}_{4} \mathrm{Si}_{5} \mathrm{O}_{18}$. Cordierite merupakan bahan yang tidak radioaktif (Cordierite Mineral Data, 2007), yang memilki sifat fisik yaitu tidak tak berwarna, biru muda, violet dan kuning dengan massa jenis 2,5 gr/cc (Smallman, 2000). Keramik Cordierite dapat dihasilkan dari berbagai bahan baku sebagai sumber Silika, diantaranya TEOS (Tetraethylortosilikat), TMOS (Tetramethylortosilikat), dan sekam padi. Selain itu, dari hasil penelitian yang telah dilakukan bahwa sampel 
Cordierite juga telah disintesis dengan Silika aktif-Alumina-talc dan KaoliniteAlumina-talc (Kurama, 2006). Cordierite yang dihasilkan dari Silika aktif menunjukan pembentukan Cordierite terjadi pada suhu sintering yang rendah sehingga energi aktivasi yang dibutuhkan juga akan rendah. Penelitian yang telah dilakukan dengan menggunakan bahan baku Silika sekam padi menunjukkan bahwa struktur Cordierite akan terbentuk seiring dengan kenaikan suhu sintering (Naskar, 2004).

\section{Silika}

Senyawa kimia Silikon Dioksida, yang dikenal dengan nama Silika merupakan Oksida Silikon dengan rumus kimia $\mathrm{SiO}_{2}$. Silika adalah salah satu bahan keramik, yang memilki daya tahan terhadap temperatur tinggi, pemuaian termal (expansion thermal) rendah dan bersifat resistant dengan nilai resistivitas $>10^{14}$ sehingga baik digunakan sebagai bahan isolator (Wikipedia, 2006). Disamping itu silika tidak larut dalam air (Timing, 1990), memilki stabilitas termal yang tinggi, dan memilki daya tahan terhadap asam dan basa.

\section{Sintering}

Sintering merupakan metode yang sering digunakan dalam pembuatan keramik, dimana kenaikan adesi di atara partikel melaui proses pemanasan. Proses sintering memerlukan pemanasan dengan suhu tinggi supaya partikel-partikel halus saling beraglomerasi menjadi bahan padat. Hampir semua bentuk keramik melalui proses pembakaran dengan temperatur tinggi dapat menghasilkan suatu tingkatan mikrostruktur yang diinginkan (Dorre dan Hubner, 1984).

\section{DTA dan XRD}

Analisis DTA (Differensial Thermal Analysis) merupakan teknik analisis yang digunakan untuk mengukur perubahan kandungan panas dengan cara merekam secara terus- menerus perbedaan temperatur antara sampel yang diuji dengan materi pembanding yang inert sebagai suatu fungsi dari perubahan temperatur (Khopkar, 1990). Sedangkan XRD (X-Ray Diffraction) adalah metode yang dapat menerangkan gambarangambaran utama struktur kisi, yaitu parameter kisi dan jenis struktur , atpi juga hal-hal lain seperti susunan atom yang berbeda pada kristal-kristal (Smallman, 1991).

\section{METODE PENELITIAN}

\section{Alat dan Bahan}

Adapun bahan yang digunakan pada penelitian ini adalah sekam padi, larutan $\mathrm{KOH} \mathrm{5 \% ,} \mathrm{Mg}\left(\mathrm{NO}_{3}\right)_{2} \mathrm{CH}_{2} \mathrm{O}, \mathrm{Al}\left(\mathrm{NO}_{3}\right)_{3} 9$ $\mathrm{H}_{2} \mathrm{O}, \mathrm{NH}_{3}$, pasta perak, dan $\mathrm{FeCl}_{3}$. Sedangkan alat yang digunakan pada penelitian ini adalah gelas ukur, labu ukur $1000 \mathrm{ml}$ dan $100 \mathrm{ml}$, kompor listrik, becker glass, batang pengaduk, spatula, corong kaca bucher, labu elenmeyer, Alumunium foil, pipet tetes, kertas saring, cawan tahan panas, kertas tisu, mortal dan pastel, $\mathrm{PH}$ meter, timbangan digital, pengayak dengan diameter $125 \mu \mathrm{m}$, penekan hidrolik, furnece, kawat, PCB, neraca digital dengan ketelitian 0,0001 g, press hidrolik, pompa vakum, amplas, DTA, $\mathrm{XRD}$, cetakan, tungku sintering, jangka sorong, multimeter dan stopwatch.

\section{Ekstraksi Silika Sekam Padi}

Sekam padi yang telah dicuci dan dikeringkan diekstraksi dalam larutan $\mathrm{KOH} 5 \%$. Sekam sebanyak 50 gram 
dimasukan ke dalam beaker glass, kemudian diberi larutan $\mathrm{KOH} 5 \%$ sebanyak $500 \mathrm{ml}$ sesuai dengan prosedur penelitian yang dilakukan sebelumnya (Ginting, 2006, Sembiring, 2006, Daifullah, 2004) hingga sekam padi terendam. Sekam padi yang telah terendam larutan $\mathrm{KOH}$ dididihkan selama 30 menit sambil terus diaduk menggunakan batang pengaduk. Setelah uap panasnya hilang, rebusan sekam ditutup dengan menggunakan Alumunium foil dan didiamkan selama 24 jam. Kemudian dilakukan pemisahan ampas sekam padi dari ekstrak sekam dengan menggunakan corong bucher. Proses ekstraksi Silika akan menghasilkan Silika yang berbentuk larutan (sol).

\section{Preparasi Cordierite}

Sebelum melakukan preparasi, sekam padi dicuci terlebih dahulu dengan air panas, agar kotoran-kotoran (zat organik) yang larut dalam air seperti batang padi, tanah, pasir dan debu dapat terlepas dari sekam padi. Setealah pencucian, sekam padi dikeringkan selama \pm 2 hari dengan suhu sekitar $35{ }^{0} \mathrm{C}$. Pengeringan dapat dilakukan dengan menggunakan oven, tetapi pengeringan dengan menggunakan matahari lebih efektif karena penyebaran panas berlangsung secara bertahap dan menyeluruh sehingga penyerapan air ke udara merata (Harsono, 2002), yang mengakibatkan kandungan Silika yang diperoleh lebih tinggi.

\section{Sintesis Coerdierite}

Pada penelitian ini akan dilakukan sintesis Cordierite dengan bahan dasar $\mathrm{Mg}\left(\mathrm{NO}_{3}\right)_{2} \quad 6 \mathrm{H}_{2} \mathrm{O}, \quad \mathrm{Al}\left(\mathrm{NO}_{3}\right)_{3} .9 \mathrm{H}_{2} \mathrm{O}$ dan Silika sol dan Silika hasil ekstraksi sekam padi dengan perbandingan 2:2:5 menggunakan pelarut air bebas ion (aquades) dan amonia $\left(\mathrm{NH}_{3}\right)$. Larutan Magnesuim Nitrat $\left(\mathrm{Mg}\left(\mathrm{NO}_{3}\right)_{2} .6 \mathrm{H}_{2} \mathrm{O}\right)$ dan Alumunium Nitrat $\left(\mathrm{Al}\left(\mathrm{NO}_{3}\right)_{3} .9 \mathrm{H}_{2} \mathrm{O}\right)$ dihidrolisis dengan menggunakan aquades sebanyak $10 \mathrm{ml}$ kemudian kedua larutan distirrer dan ditambahkan dengan $\mathrm{NH}_{3}$ (amonia) yang terus stirrer pada temperatur ruang agar larutan homogen. Selanjutnya, larutan dipanaskan pada suhu $80 \pm 1{ }^{0} \mathrm{C}$ hingga mencapai $\mathrm{pH} \mathrm{3,2}$ dengan kekentalan $25 \mathrm{mPa}$ s dan larutan terlihat jernih dan transparan. Hasil campuran ini menghasilkan komponen MagnesiaAlumina. Larutan bi-component (Magnesia-Alumina) yang diperoleh kemudian dicampurkan dengan larutan (sol) Silika. Hasil campuran yang diperoleh akan bersifat netral karena larutan Magnesia-Alumina bersifat asam dan sol Silika bersifat basa, dapat dikatakan bersifat netral apabila telah terjadi endapan yang berupa gel, gel ini didefinisikan sebagai Cordierite gel. Cordierite gel yang diuperoleh kemudian dipanaskan pada suhu $90{ }^{\circ} \mathrm{C}$ sambil diaduk terus-menerus sampai terbentuknya dry gel dan akhirnya akan membentuk bubuk Cordierite. Setelah itu dihaluskan dengan menggunakan mortar dan pastle, dan disaring dengan menggunakan ayakan berdiameter $125 \mu \mathrm{m}$, agar didapat yang lebih halus.

\section{Sintering}

Proses sintering dilakukan dengan menggunakan tungku pembakaran (furnace) listrik yang dapat diatur sesuai dengan yang diinginkan. Temperatur yang digunakan dalam proses sintering ini adalah $1000{ }^{\circ} \mathrm{C}, 1200{ }^{\circ} \mathrm{C}$, dan $1400{ }^{\circ} \mathrm{C}$ dengan penahanan selama 6 jam. Sintering dapat meningkatkan kekuatan bahan 
karena pada saat sintering terjadi pertumbuhan butiran tersebut melebur menjadi satu.

\section{Karakterisasi}

Pertama dilakukan uji DTA. Langkahlangkah kerja DTA yaitu dengan menyiapkan cawan platina kosong yang digunakan sebagai sampel referensi, dan memasukan serbuk sampel ke dalam cawan platina sebagai sampel yang akan diuji. Selanjutnya kedua cawan platina diletakkan pada posisi vertikal di sampel holder dengan posisi furnace diputar ke arah sampel holder yang dilanjutkan dengan mengatur setting temperatur yaitu $\mathrm{T}_{\text {start }}=50{ }^{\circ} \mathrm{C}, \mathrm{T}_{\text {pengukuran }}=1300{ }^{\circ} \mathrm{C}$ heating read (kenaikan suhu $=10{ }^{0} \mathrm{C} /$ menit). Kemudian tombol power furnace di tekan pada posisi " $O N$ " untuk pemanasan akan bekerja sesuai dengan program yang telah diatur, saat inilah grafik pada monitor komputer akan terlihat dan akan diamati sampai temperatur $\mathrm{T}_{\text {pengukuran }}=$ tercapai menurut program yang telah diatur. Apabila $\mathrm{T}_{\text {pengukuran }}$ telah tercapai maka power furnace dapat dimatikan yaitu pada posisi " $O F F$ " dan selanjutnya dilakukan print hasil pengukuran.

Selanjutnya uji XRD. Pola difraksi sinar-X dihasilkan oleh difraktometer sinar-X dengan panjang gelombang yang digunakan sebesar $1,54056 \AA$. Alat tersebut diatur pada kondisi eksperimen yaitu tegangan $40 \mathrm{kV}$, arus $30 \mathrm{~mA}$, celah divergen $1^{0}$, celah penerima $2^{0}$. Rentang data difraksi (2 theta) adalah $20-120^{\circ}$, dengan tipe scanning continue, step size 0,05 dan waktu 1 detik per-step. Selanjutnya pola difraksi sinar-X dianalisis secara kualitatif menggunakan metode Search Macth Analysis, kemudian hasilnya dibandingkan dengan data standar

\section{Uji Tahanan (Resistansi)}

Pengukuran tahanan keramik Cordierite yang pada suhu $1000{ }^{0} \mathrm{C}, 1200{ }^{\circ} \mathrm{C}$, dan $1400{ }^{\circ} \mathrm{C}$ dengan keramik Cordierite untuk melihat tahanan sebagai material isolator listrik. Adapun langkah pengukuran tahanan pada sample sebagai berikut rangkaian pengukuran tahanan ditunjukkan seperti Gambar 1.

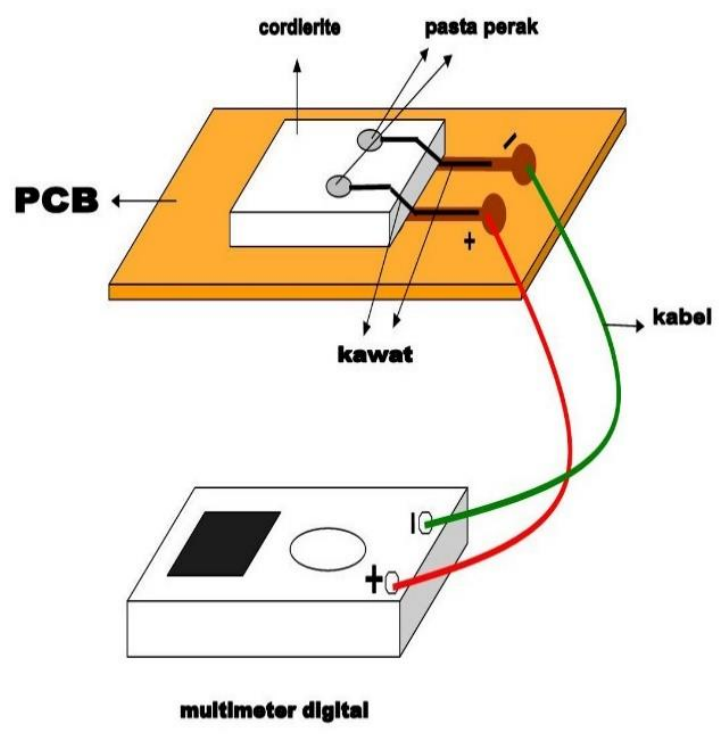

Gambar 1. Rangkaian pengukuran tahanan pada keramik Cordierite berbasis Silika sekam padi sebagai material isolator listrik.

\section{HASIL DAN PEMBAHASAN}

\section{Hasil Ektraksi Silika Sekam Padi}

Ekstraksi Silika yang diperoleh dengan mencapurkan 50 gram sekam padi ke dalam $500 \mathrm{ml} \mathrm{KOH} \mathrm{5 \%} \mathrm{yang} \mathrm{selanjutnya}$ dipanaskan pada suhu $100{ }^{\circ} \mathrm{C}$ selama 30 menit dari hasil ekstraksi tersebut diperoleh filtrat kurang lebih $390 \mathrm{ml}$ yang terlihat coklat kehitaman karena adanya zat tanin (selulosa dan lignin) atau zat yang tidak diinginkan (pengotor) yang terkandung di dalam sekam padi di antaranya karbon, natrium, kalium, besi dan lain-lain (Sigit Nugraha, 2001). 


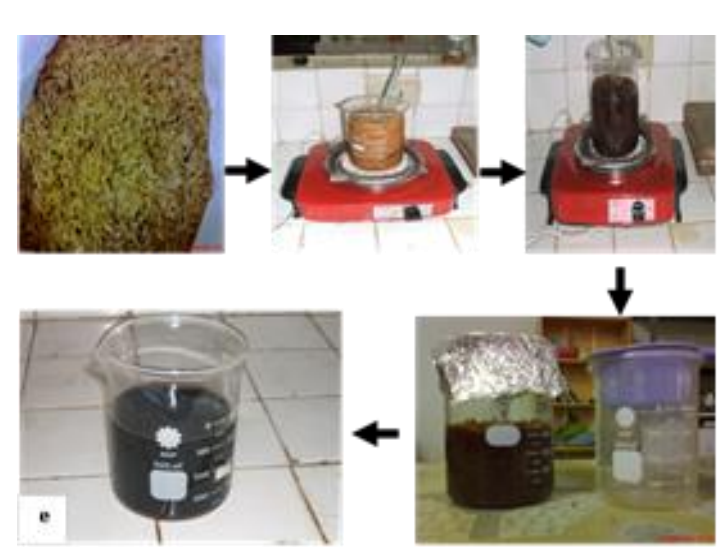

Gambar 2. Filtrat (sol silica) didapat dari proses ektraksi sekam padi dengan hasil ektraksi berwarna coklat kehitam-hitaman.

Filtrat hasil ekstraksi silika sekam padi (Sol Silika) seperti yang ditunjukkan pada Gambar 2.

\section{Hasil Sintesis Coerdierite}

Tahap awal sintesis Cordierite adalah dengan mencampurkan bahan dasar Magnesium Nitrat Hydrate $\left(\mathrm{Mg}\left(\mathrm{NO}_{3}\right)_{2} .6 .12 \mathrm{H}_{2} \mathrm{O}\right)$ sebanyak 26,3 gram dan Alumunium Nitrat Hydrate $\left(\mathrm{Al}\left(\mathrm{NO}_{3}\right)_{2} .9 .15 \mathrm{H}_{2} \mathrm{O}\right) \quad 39,3$ gram. Kedua bahan serbuk tersebut dihidrolisis dengan aquades sebanyak $10 \mathrm{ml}$ sehingga menghasilkan sol Magnesium Nitrat dan sol Alumunium Nitrat, dimana masingmasing larutan $10 \mathrm{ml}$ tersebut mengandung 3 gram Magnesium dan Alumunium. Selanjutnya dengan perbandingan yang sama yaitu $10 \mathrm{ml}$ kedua larutan dicampur. Kemudian larutan tersebut ditambahkan $\mathrm{NH}_{3}$ secara bertahap yang disertai dengan pemanasan pada suhu $80{ }^{\circ} \mathrm{C}$. Penambahan $\mathrm{NH}_{3}$ berfungsi untuk meningkatkan $\mathrm{pH}$ larutan yang berawal dari $\mathrm{pH}=1$ hingga $\mathrm{pH}=3$ yang diukur menggunakan kertas lakmus, selain itu penambahan tersebut dilakukan untuk mempercepat reaksi sehingga diperoleh larutan yang bening, putih, dan transparan. Hasil ini sesuai dengan penelitian sebelumnya, (Naskar dan Chartterjee, 2004). Dimana larutan yang diperoleh disebut dengan sol Magnesia-Alumina. Hasil ini mengindikasikan dalam larutan telah terbentuk ion-ion $\mathrm{Mg}$ dan $\mathrm{Al}$. Hasil ini ditunjukkan pada Gambar 3.

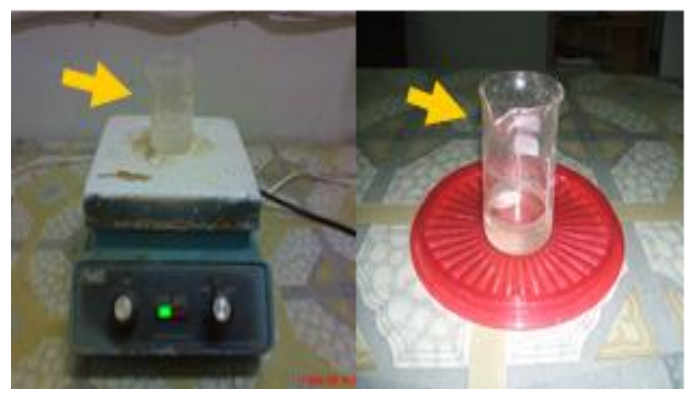

Gambar 3. Hasil campuran Magnesium Nitrat Hydrate dengan Aluminium Nitrat Hydrate.

Tahap selanjutnya adalah sintesis Coerdierite, sol Magnesium-Alumina ditambahkan silika hasil ekstraksi (filtrat) dalam $100 \mathrm{ml}$ terkandung 7,5 gram Silika. Sehingga perbandingan ketiga bahan baku $\mathrm{Mg}, \mathrm{Al}$ dan $\mathrm{SiO}_{2}$ adalah 2 : 2 : 5. Dan hasilnya ditunjukkan pada Gambar 4. 


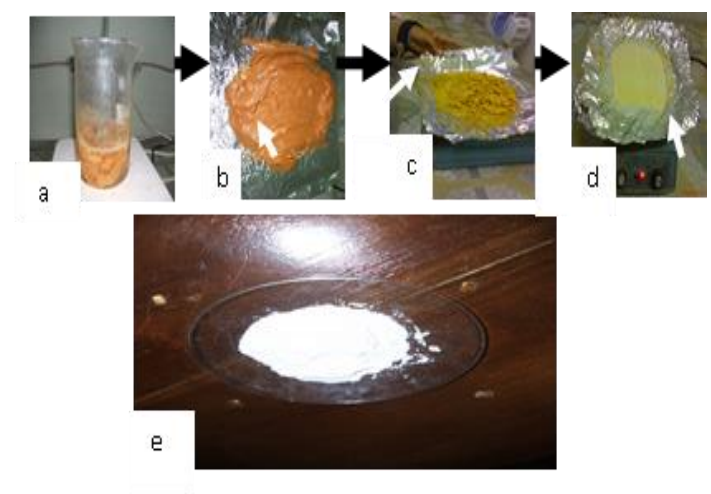

Gambar 4. Hasil preparasi dan sintesis Cordierite (a) Gel Cordierite sebelum proses pengeringan, (b), (c), dan (d) adalah gel Cordierite pada proses pengeringan dan (e) Serbuk Cordierite yang berwarna putih.

\section{Hasil Sintering}

Sampel yang masih berupa serbuk kemudian dibentuk pellet dengan menggunakan pressing hidrolik pada tekanan 2 ton. Serbuk Cordierite yang telah menjadi pellet kemudian dilakukan proses sintering dengan suhu $1000{ }^{\circ} \mathrm{C}$, $1200{ }^{\circ} \mathrm{C}$ dan $1400{ }^{\circ} \mathrm{C}$ dengan penahanan selama 6 jam. Pellet ditempatkan di dalam cawan crucible kemudian disintering menggunakan furnace. Dari perlakuan sintering didapatkan hasil yang ditunjukan pada Gambar 5.
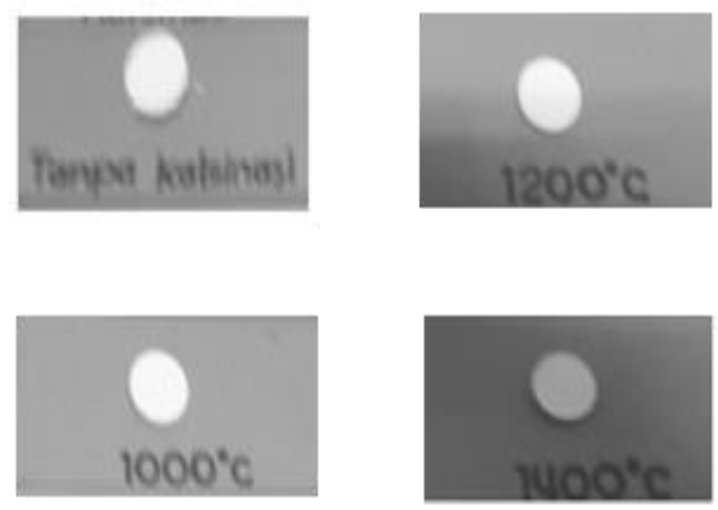

Gambar 5. Hasil sintering

\section{Hasil Karakterisasi DTA}

Hasil analisis DTA sampel keramik Cordierite sintering pada suhu sintering $1000{ }^{\circ} \mathrm{C}, 1200{ }^{\circ} \mathrm{C}$, dan $1400{ }^{\circ} \mathrm{C}$ masingmasing ditunjukkan pada Gambar 6. Hasil DTA menunjukkan puncak endoterm pada sintering $1000{ }^{\circ} \mathrm{C}$ adalah pada suhu 130.95, pada suhu sintering $1200{ }^{\circ} \mathrm{C}$ pada suhu 125.71, dan suhu $1400{ }^{\circ} \mathrm{C}$ pada suhu123.1. Dan adanya puncak-puncak eksoterm pada suhu sintering $1000{ }^{\circ} \mathrm{C}$ yaitu 107.16, 283.21 dan suhu sintering $1200{ }^{\circ} \mathrm{C}$ yaitu 277.29 dengan kenaikan suhu sintering semakin besar terjadi proses kristalisasi dan menuju kesetimbangan dengan munculnya puncak pada suhu sintering $1400{ }^{\circ} \mathrm{C}$ yaitu suhu 321,543 dan 1369 yang mengindikasikan terbentuknya keramik Cordierite yang sesuai dengan hasil Chatterjee dan Naskar (2004).

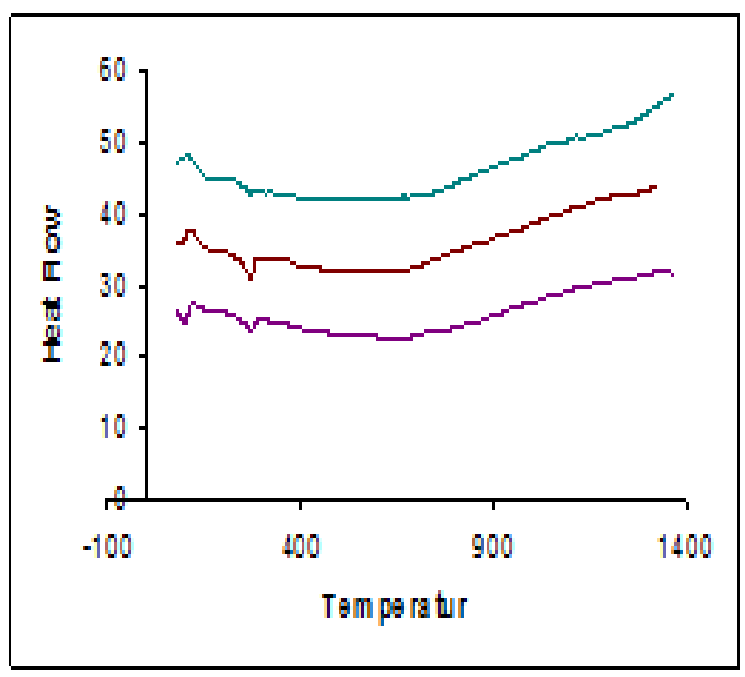

Gambar 6. Grafik hasil DTA. (a) Sintering $1000{ }^{\circ} \mathrm{C}$, sintering $1200{ }^{\circ} \mathrm{C}$, dan (c) sintering $1400{ }^{\circ} \mathrm{C}$

\section{Hasil karakterisasi XRD}

Analisis struktur kristal pembentukkan keramik Cordierite dari bahan Silika sekam padi tanpa sintering dan sintering pada suhu $1000^{\circ} \mathrm{C}, 1200{ }^{\circ} \mathrm{C}$, dan $1400{ }^{\circ} \mathrm{C}$. 
Dimana masing-masing suhu ditandai dengan warna merah muda adalah suhu $1000^{\circ} \mathrm{C}$, abu-abu adalah $1200^{\circ} \mathrm{C}$, dan orange $1400^{\circ} \mathrm{C}$. Berdasarkan Gambar 7 ditunjukkan hasil bentuk gelombang difraksi sinar-X. Dimana pada suhu tanpa sintering fasa cordierite belum begitu terbentuk mendominasi puncak intensitasnya, namun tampak teridentifikasi pembentukkan $\mu$-cordierite. Sedangkan pada sintering dengan suhu $1000{ }^{0} \mathrm{C}$ munculnya fasa $\alpha$-cordierite akibat perubahan struktur yang dialami sampel setelah perlakuan perubahan suhu dan membuatnya timbul fasa-fasa kristal yang baru. Dimana puncak difraksi muncul pada sudut $2 \theta=10,720^{\circ}$ dengan intensitas sebesar 385 .

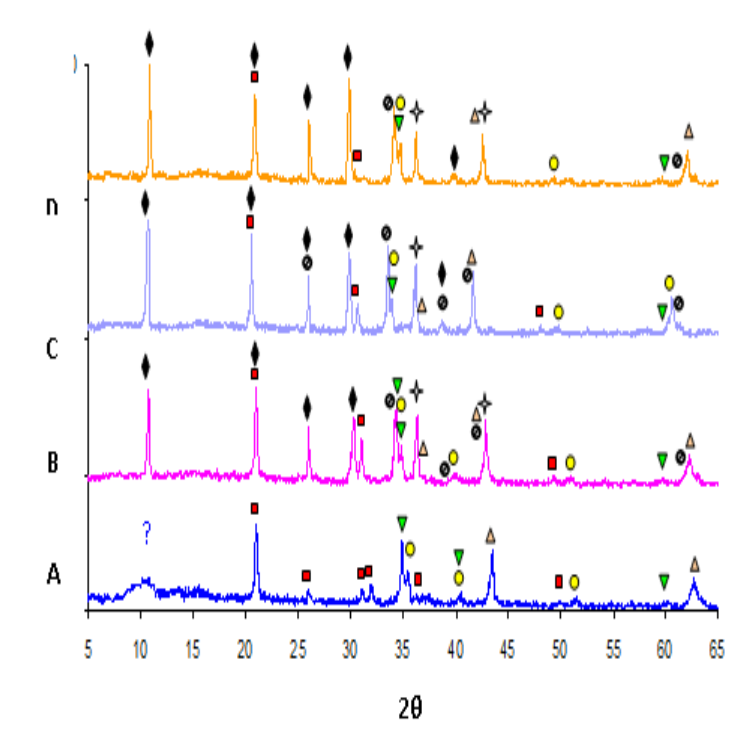

Gambar 7. Bentuk gelombang difraksi menggunakan XRD pada sampel sebelum sintering ((A) tanpa sintering) dan setelah sintering ((B) $1000{ }^{\circ} \mathrm{C},(\mathbf{C}) 1200{ }^{\circ} \mathrm{C},(\mathbf{D}) 1400$ ${ }^{\circ} \mathrm{C}$ ) terbentuk fasa yaitu (1) fasa ${ }^{\mu}$. cordierite? terbentuk pada sebelum sintering dan fasa $\alpha$-cordierite $\bullet,(2)$ fasa cristobalite $\square$, (3) fasa corudum $\bullet$, (4) fasa chlorite $\circ$, (5) fasa moisanite $\nabla$, (6) fasa spinel $\diamond$, dan (7) fasa periclase $\Delta$.
Untuk sampel dengan sintering $1200^{\circ} \mathrm{C}$ jika dilihat bentuk gelombang difraksi menggunakan sinar-X. dimana fasa $\mu$ cordierite tetap mendominasi dan besar intensitasnya semakin bertambah yaitu terletak pada sudut $2 \theta=10,700^{\circ}$ dengan besar intensitasnya sebesar 435. Seiring dengan kenaikan suhu sintering yaitu pada sampel sintering $1200^{\circ} \mathrm{C}$ dan sampel sintering $1400^{\circ} \mathrm{C}$ menunjukkan bahwa memiliki puncak difraksi atau intensitas yang berbeda dengan sampel sintering $1000^{\circ} \mathrm{C}$. Hal ini diindikasikan bahwa sampel $\alpha$-cordierite cenderung mendominasi dalam munculnya puncak difraksi (sering muncul) dan nilai intensitasnya semakin meningkat. Perubahan yang sangat signifikan terjadi pada perubahan sampel yang struktur kristalnya menjadi fasa $\alpha$-cordierite seluruhnya. Hal ini merupakan bagian indikasi yang hampir sama dengan penelitian yang dilakukan sebelumnya, dimana pada suhu $1400^{\circ} \mathrm{C}$ terdapat puncak difraksi yang menunjukan fasa $\alpha$ cordierite

\section{Hasil Uji Tahanan (Resistansi)}

Karakteristik tahanan dilakukan untuk mengetahui besar resistansi pada bahan tersebut. Karakteristik tahanan ini dilakukan pada sampel yang telah disintering dengan suhu sintering $1000{ }^{\circ} \mathrm{C}$, $1200{ }^{\circ} \mathrm{C}$ dan $1400{ }^{\circ} \mathrm{C}$ yang dapat disajikan pada Tabel 1. 
Tabel 1. Nilai Tahanan

\begin{tabular}{|c|c|c|c|}
\hline $\begin{array}{l}\text { wakty } \\
\text { (mentit) }\end{array}$ & $\begin{array}{l}\text { Suhv Sintering } \\
1000^{\circ} \mathrm{C}(\mathrm{M})\end{array}$ & $\begin{array}{l}\text { Sulm Sintering } \\
1200^{\circ} \mathrm{C}(\mathrm{MQ})\end{array}$ & $\begin{array}{l}\text { Suhv Sintering } \\
1300^{\circ} \mathrm{C}(\mathrm{M})\end{array}$ \\
\hline 0 & 13.6667 & 10.3333 & 29.3333 \\
\hline 5 & 13.3333 & 10.3333 & 33 \\
\hline 10 & 13,6667 & 10,3333 & 34,6667 \\
\hline 15 & 14 & 10.3333 & 36.6667 \\
\hline 20 & 14 & 10.6667 & 39.6667 \\
\hline 25 & 14 & 10.6667 & 41 \\
\hline 30 & 14 & 10.6667 & 40.6667 \\
\hline 35 & 14 & 10.6667 & 41 \\
\hline 40 & 14 & 10.6667 & 41 \\
\hline 45 & 14 & 10,6667 & 43,6667 \\
\hline 50 & 14 & 10,6667 & 42.6667 \\
\hline 55 & 14 & 10,6667 & 43.3333 \\
\hline 60 & 14 & 10.6667 & 42 \\
\hline
\end{tabular}

Berdasarkan hasil pengukuran tahanan $(\mathrm{R})$ pada sampel didapatkan grafik pada Gambar 8. Sama halnya pada karakteristik sebelumnya yaitu DTA dan XRD, pada karakteristik ini dilakukan pada keramik Cordierite pada suhu sintering $1000{ }^{0} \mathrm{C}, 1200{ }^{\circ} \mathrm{C}$, dan $1400{ }^{\circ} \mathrm{C}$. Dalam karakteristik tahanan ini dilakukan menggunakan multimeter dalam satuan $\mathrm{M} \Omega$. Hasil yang diperoleh dari karakteristik tahanan, dapat diperlihatkan pada gambar 8. Pada suhu sintering 1000 ${ }^{0} \mathrm{C}$ diperoleh nilai rata-rata $\mathrm{R}$ setiap kenaikan waktu sebesar $13.89 \mathrm{M} \Omega$ dan begitu pula untuk suhu sintering $1200{ }^{0} \mathrm{C}$ untuk setiap kenaikan waktu diperoleh nilai rata-rata $\mathrm{R}$ yaitu sebesar $10.56 \mathrm{M} \Omega$.

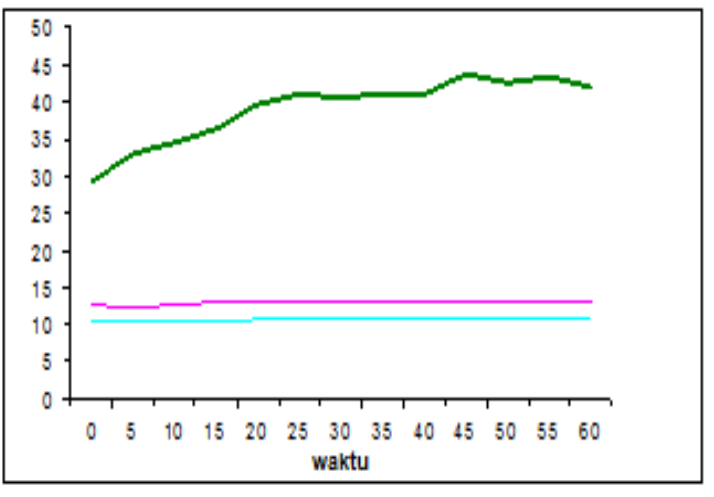

Gambar 8. Grafik tahanan (a) suhu sintering $1000{ }^{\circ} \mathrm{C}$, (b) suhu sintering $1200{ }^{\circ} \mathrm{C}$ dan (c) suhu sintering $1400{ }^{\circ} \mathrm{C}$.

Namun berbeda untuk nilai $\mathrm{R}$ pada suhu sintering sebesar $1400{ }^{0} \mathrm{C}$, untuk setiap kenaikan waktu diperoleh nilai $\mathrm{R}$ cenderung naik. Nilai $\mathrm{R}$ yang diperoleh pada suhu sintering $1400^{\circ} \mathrm{C}$ berkisar antara 29,33 - 43,67 M $\Omega$ yang diukur dalam selang waktu 0-60 menit. Hasil DTA menunjukkan suhu sintering $1400 \quad{ }^{0} \mathrm{C}$ merupakan suhu terbaik untuk menghasilkan Cordierite, namun dalam karakteristik tahanan pada suhu sintering $1400{ }^{\circ} \mathrm{C}$ menghasilkan nilai tahanan yang tidak konstan. Terjadinya perbedaan nilai $\mathrm{R}$ untuk suhu $1400{ }^{\circ} \mathrm{C}$ pada setiap kenaikan waktu dikarenakan karena homogenitas pada suhu sintering $1400{ }^{\circ} \mathrm{C}$ sangat rendah, homogenitas terbaik didapat pada suhu sintering $1000{ }^{\circ} \mathrm{C}$ sehingga menghasilkan nilai $\mathrm{R}$ yang konstan pada setiap kenaikan waktu. 
Tabel 2. Nilai resistivitas tiap suhu sintering.

\begin{tabular}{cccc}
\hline $\begin{array}{c}\text { Wa } \\
\text { ktu }\end{array}$ & $\begin{array}{l}\mathbf{1 0 0 0}^{\mathbf{}} \mathbf{C} \\
\mathbf{M} \mathbf{\Omega . m}\end{array}$ & $\begin{array}{l}\mathbf{1 2 0 0}^{\circ} \mathbf{C} \\
\mathbf{M \Omega . m}\end{array}$ & $\begin{array}{c}\mathbf{1 3 0 0}^{\mathbf{}} \mathbf{C} \\
\mathbf{M} \mathbf{\Omega} . \mathbf{m}\end{array}$ \\
\hline 0 & 0,34 & 0,52 & 1,21 \\
5 & 0,33 & 0,52 & 1,36 \\
10 & 0,33 & 0,52 & 1,43 \\
15 & 0,35 & 0,52 & 1,50 \\
20 & 0,35 & 0,53 & 1,64 \\
25 & 0,35 & 0,53 & 1,69 \\
30 & 0,35 & 0,53 & 1,68 \\
35 & 0,35 & 0,53 & 1,69 \\
40 & 0,35 & 0,53 & 1,69 \\
45 & 0,35 & 0,53 & 1,80 \\
50 & 0,35 & 0,53 & 1,76 \\
55 & 0,35 & 0,53 & 1,78 \\
60 & 0,35 & 0,53 & 1,73 \\
\hline
\end{tabular}

Selanjutnya berdasarkan hasil karakteristik tahanan, maka didapatkan nilai resistivitas dari sampel Cordierite pada Tabel 2. Dari tabel tersebut terlihat bahwa resistivitas semakin besar berdasarkan kenaikan suhu sintering. Besar nilai resistivitas memberikan informasi bahwa bahan tersebut bersifat isolator listrik.

\section{SIMPULAN DAN SARAN \\ Simpulan}

Kenaikan suhu sintering terhadap pembentukan struktur Cordierite semakin meningkat ditandai semakin terbentuknya struktur $\alpha$-Cordierite dengan intensitas tinggi dan gugurnya struktur lain pada hasil X-Ray Diffraction (XRD).

Kenaikan suhu sintering terhadap sifat termal Cordierite semakin stabil ditandai dengan puncak endoterm dan eksoterm yang semakin kecil pada hasil Differential Thermal Analysis (DTA).
Meningkatnya nilai resistivitas sampel Cordierite setiap kenaikan suhu sinte ring. Semakin stabilnya sifat termal Cordierite mengakibatkan semakin terbentuknya struktur $\alpha$-Cordierite dengan intensitas tinggi dan gugurnya struktur lain berdasarkan hasil DTA dan XRD.

Kestabilan Cordierite pada termal tinggi yang ditunjukkan pada hasil DTA mengakibatkan nilai resistivitas sampel Cordierite meningkat setiap kenaikan suhu sintering. Kestabilan pada termal tinggi dan terbentuknya struktur Cordierite yang menghasilkan nilai resistivitas yang semakin tinggi setiap kenaikkan suhu sintering menunjukkan bahwa Cordierite sebagai material isolator listrik.

\section{Saran}

Dalam melakukan penyimpanan bahan sampel Cordierite dianjurkan agar tetap kering dan bersih. Pada proses pressing hidrolik menggunakan kekuatan tekanan lebih besar dari 2 Ton, agar sampel lebih kuat dan padat. Pada pengukuran tahanan disarankan agar menggunakan multimeter digital dengan daya hitung di atas Mega Ohm agar perhitungan lebih teliti

Dianjurkan melakukan sintering di atas suhu sintering $1400{ }^{\circ} \mathrm{C}\left(1500{ }^{\circ} \mathrm{C}-1700^{\circ} \mathrm{C}\right)$ untuk mengetahui nilai fase, homogenitas, dan resistivitas pada keramik Cordierite agar mendapatkan hasil yang maksimum. Disarankan melakukan beberapa karakteristik lainnya seperti FTIR, SEM, dan sebagainya.

\section{UCAPAN TERIMA KASIH}

Terimakasih kepada pihak Laboratorium Fisika dan Kimia Fakultas MIPA Universitas Lampung serta kepada pihak Laboratorium P3IB Batan Serpong 
atas bantuan alat dalam pelaksanaan pressing sampel, uji tahanan, uji DTA, dan uji XRD.

\section{DAFTAR PUSTAKA}

Amick, J. A., Purification of Rice Husk Ash a Source of Solar Grade Silicon for solar Cells., J. Electrochem. Soc. 129 (1982) 864866.

Badan Pusat Statistik Provinsi Lampung. 2004. Sensus Pertanian (SE' 04). Lampung

Bose, S; H, Acharya, H, Banerjee, (1993), Electrical Thermal Thermoelectric and Related of Magnesium Silicate Semiconductor Prepared from Rice Husk, Journal of Material Science, 28, 5461-5468.

Chattejee, M, M. K, Naskar. 2006. Sol-Gel Synthesis of Lithium Alumunium Silicate Powders; The Effect of Silica Source, Ceramic International, 32, 623-632.

Cordierite Information-Provided by Insaco Inc, 215-536-3500. High Precision Machining of Hard Materials. 2007. Quakertown, PA 189519006 USA.

Daifullah, A. A. M., Awwad, N. S and ElReefy, S. A. 2004. Purification of Wet Phosphoric Acid from Ferric Ions Using Modified Rice Husk. Chemical Engineering and Processing, 43: 193-201.

Della, V. P; Kuhn, I; Hotza, D (2002)," rusk Husk Ash an Alternate Source for Active Silica Production", Materials Letters, 57. 818-821.

Dorre and Hubner, 1984, Alumina, Library of Congress cataloging in Publication Data, cambridge, USA.
Ginting, I, W, Simanjuntak, S, Sembiring, E, Trisnawati. 2006. Karakteristik Silika Sekam Padi yang diperoleh dengan metode Ekstraksi. Universitas Lampung. Bandar Lampung.

Harsono, H. 2002. Pembuatan Silika Amorf dari Limbah Sekam Padi. Jurnal Ilmu Dasar.Vol3 No. 2. FMIPA Universitas Jember. Jawa Timur Hal 98-102.

Kalapathy, C; Protor, A and Shultz, J (2000), "A Simple Method for Production of Pure Silica from Rice Husk Ash", Biosource Technology, 73, 257-264.

Khopkar, S, M. 1990. Konsep dasar Kimia Analitik. Universitas Indonesia. Jakarta.

Kurama, S, H, Kurama. 2006. The Reaction Kinetics of Rice Husk Based Cordierite Ceramics. Turkey. Ceramic International xxx (2006) xxx-xxx. CERI-No of Pages 4.

Laboratorium Uji Kendali Produk. PT. Bukit Asam Tarahan, Panjang Bandar Lampung.

Naskar, M. K, M, Chatterjee, M. 2001. A Novel Process for the Synthesis of Cordierite (Mg2Al4Si5O18) Powders from Rice Husk Ash and other Sources of Silica and their Comparative Study. Kolkota India. Jurnal of the European Ceramics Society 24 (2004) 3499-3908.

Oktavianty, S.W., Sembiring, S., Simanjuntak, W., dan Karo-karo, P. 2016. Pengaruh Penambahan Alumina $\left(\mathrm{Al}_{2} \mathrm{O}_{3}\right)$ 0, 10, dan $15 \mathrm{wt} \%$ terhadap Karakteristik Konduktivitas Listrik dan Mikrostruktur Cordierite 
$\left(2 \mathrm{MgO} .2 \mathrm{Al}_{2} \mathrm{O}_{3} .5 \mathrm{SiO}_{2}\right) \quad$ Berbasis Silika Sekam Padi. Jurnal Teori dan Aplikasi Fisika, Vol. 04, No .02, Tahun 2016, 207-212.

Sembiring, S. 2006. Karakterisasi Silika

Sekam Padi sebagai Bahan

Keramik dengan Teknik Sintering.

Universitas Lampung. Bandar Lampung.

Shinohara, Y and Kohyama, N (2004),"

Quantitative Analysisof Tridymite and Crystobalite Crystalized in Rice Husk Ash by Heating", National Institute of Health.

Siriluk and Yuttapong, structure of Mesoporous MCM-41 Prepared from Rice Husk Ash, Asian Symposium on Visualization, Chaingmai, Thailand. 2005.
Smallman, R, E. 2000. Metalurgi Fisik Modern dan Rekayasa material. Edisi keenam. Terjemahan Sriati Djaprie, Erlangga. Jakarta.

Sofyan, Imam G.G., 2012. Sintesis dan Karakterisasi Bahan Keramik Cordierite dari Abu Sekam Padi. Skripsi. UNS.

Sun, L dan Gong, K. 2001. Silicon-Based Materials from Rice Husks and Applications. Eng. Chem. Res. 40: 5861-5877.

Timmings, R. L. 1990, Enginering Material, Longman, England.

Yalcin, N. Sevinc. V. 2000. Studies on Silica Obtained from Rice Husk. Sakarya University, Arts and Sciences Faculty, Chemistry Departement, Serdivan Turkey. 